P-ISSN: 0216-4396 Jurnal Tapis: Jurnal Teropong Aspirasi Politik Islam 15(7) (2019) 142170

e-ISSN: 2655-6057 https:// http://ejournal.radenintan.ac.id/index.php/TAPIs/index

\title{
STUDI KOMPARASI TERHADAP FILM DOKUMENTER SEBAGAI MEDIUM PROPAGANDA TERKAIT INSIDEN KAPAL "PUEBLO" YANG DILAKUKAN KOREA UTARA DAN AMERIKA SERIKAT
}

\author{
Dinda Rizkimawati, Indra Kusumawardhana \\ London School of Public Relations Jakarta, Universitas Pertamina \\ dindarizkimawati59@gmail.com, kusumawardhana.up@gmail.com
}

Diterima 09032019 Disetujui 09062019 Dipublikasikan 23062019

Abstract: The framing of the North Korea's documentary capture of the "Pueblo" vessel by North Korea on January 23, 1968, the North Korean documentary tried to show a form of legitimacy while the United States documentary film showed a form of delegitimation aimed at instilling a message in the minds of the wider community through opinions to gain recognition .

Abstrak :Pembingkaian film dokumenter penangkapan kapal "Pueblo" milik Amerika Serikat oleh Korea Utara pada 23 Januari 1968, film dokumenter Korea Utara berusaha menunjukan bentuk legitimasi sedangkan film dokumenter milik Amerika serikat menampilkan bentuk delegitimasi hal ini bertujuan untuk menanamkan pesan dibenak masyarakat luas melalui opini untuk mendapatkan pengakuan.

Keyword: Delegitimation, Framing, Legitimacy, Pueblo.

\section{PENDAHULUAN}

Pada tanggal 23 Januari 1968 terjadi sebuah insiden penangkapan kapal Amerika Serikat bernama USS Pueblo diperairan Korea Utara yaitu dekat dengan pulau Ryo dari laut Wonsan. 


\section{Dinda Rizkimawati: STUDI KOMPARASI TERHADAP.....}

Mengutip pemberitaan BBC (Hadjimatheou, 2012), USS Pueblo merupakan satu-satunya kapal milik Angkatan Laut Amerika Serikat di dunia yang ditangkap oleh negara asing dengan tuduhan pelanggaran teritorial. USS Pueblo melakukan kegiatan spionase setelah menyusup ke perairan (390 17' 4" Lintang Utara, 1270 46' 9" Bujur Timur) 12 kilometer dari pulau kecil Ryo dekat laut Wonsan. ${ }^{1}$ USS Pueblo ditangkap Angkatan Laut Korea Utara ketika melakukan misi pemantauan di perairan barat Korea Utara. Setelah pemerintah Amerika Serikat mengakui kesalahan dan meminta maaf atas insiden itu. Korea Utara membebaskan 82 awak USS Pueblo serta satu awak kapal yang meninggal akibat penembakan, para awak kapal dibebaskan pada 23 Desember 1968. Dua tahun lalu pemerintah Korea Utara memindahkan Pueblo dari Sungai Taedong ke Sungai Potonggang. $^{2}$

Insiden Pueblo adalah peringatan yang menyakitkan atas salah perhitungan dan kebingungan, serta permusuhan yang belum terselesaikan. Melalui insiden ini, Korea Utara dan AmerIka Serikat sebagai dua negara yang bertikai, memproduksi sebuah film dokumenter yang berisikan fakta, kronologi, dan kebenaran menurut Korea Utara dan Amerka Serikat terkait insiden kapal. Film dokumenter tersebut dipublikasikan melalui saluran resmi milik Korea Utara dan Amerika Serikat di Youtube. Terindikasi dari tujuan pembuatan film tersebut adalah untuk membentuk opini masyarakat serta mempropaganda melalui film atas peristiwa tersebut untuk mendapatkan legitimasi dan delegitimasi.

Publikasi Korea Utara melalui Koryo Media di situs Youtube, dengan judul "American spy ship "Pueblo" (1999) diunggah pada tanggal 3 Juni 2014, film dokumenter yang berdurasi 13:56,

1 “Hadjimatheou, C. (23 Januari 2012,). Sailor recalls 1968 North Korean capture of USS Pueblo. Diakses dari BBC: http://www.bbc.com/news/world-asia16650683.,"

2 "RMOL, dapat diakses pada alamat

http://www.rmol.co/read/2014/04/19/151865/770/Film-Insiden-Pueblo-1968.

Terakhir akses September 2018.," 


\section{Dinda Rizkimawati: STUDI KOMPARASI TERHADAP.....}

menceritakan awal kejadian insiden kapal Pueblo, sebuah kapal matamata bersenjata milik Amerika Serikat yang sekarang bersandar di tepi Sungai Pothong di Pyogyang, sebagai saksi sejarah di era pertunjukan senjata. Kapal tersebut menyusup ke perairan teritorial sejauh 7,6 mil dari Pulau Ryo dekat Wonsan dan terlibat dalam spionase di siang hari pada tanggal 23 Januari 1968. Pueblo dilengkapi dengan fasilitas teknis terbaru untuk tujuan pengintaian sehingga memungkinkan pertukaran informasi dengan segera ke kantor pusat mengenai fasilitas militer maritim dan darat DPRK di dalam wilayah teritorial dan gerakan mereka. Kapal tersebut direbut oleh Angkatan Laut Tentara Rakyat Korea pada bulan Januari 1968 saat melakukan tindakan spionase. ${ }^{3}$

Melalui film dokumenter Korea Utara yang menceritakan kronologi insiden penangkapan "Pueblo" di tahun 1968, Amerika Serikat sebagai negara yang mengalami penagkapan. Akhirnya memberikan respon terhadap film dokumenter yang dikeluarkan oleh Korea Utara pada tahun 1972. Isi dari film dikumenter milik Amerika Serikat yang menceritakan insiden kapal Pueblo yang di publikasikan melaui US National Archives, dengan judul The Pueblo Incident: Analysis of the North Korean Evidence, dipublikasikan pada tanggal 22 Desember 2010, film dokumenter yang berdurasi 28:23 dibawakan oleh Letnan Douglas M Hackett merupakan Officer of Naval Intelligence, membahas dua aspek dalam Insiden Pueblo pertama mengenai penyitaan USS Pueblo dan kedua analisis bukti dari Korea Utara. USS Pueblo berlayar dari Sasebo Jepang pada tanggal 11 Januari 1968, menurut laporan yang dikirimkan pada tanggal 23 Januari dan mengakhiri area operasinya di Mars, Venus, dan Pluto pada tanggal 12. Pueblo memiliki misi untuk mengumpulkan data tentang instalasi elektronik di sepanjang pantai timur Korea seperti yang diperintahkan. Perintah belayar untuk USS Pueblo memiliki instruksi khusus bahwa sambil melakukan tes. Titik pendekatan

3 "Youtube, dapat diakses pada alamat

https://www.youtube.com/watch?v=q9ZPCwDeSFU," t.t. 


\section{Dinda Rizkimawati: STUDI KOMPARASI TERHADAP.....}

terdekatnya adalah tidak lebih dari 13 mil laut daratan Korea Utara atau pulau lepas pantai.

Dalam menggambarkan pengkapan tersebut, kapal Korea Utara Sub-chaser Sol telah ditemui pada pukul 12 siang waktu Korea Utara dan menempatkan pada 15.8 mil laut dari daratan terdekat pulau Hongdo dari Korea Utara. Sub-chaser 35 melaporkan posisi ke stasiun pada siang hari dari pantai dan ini sekitar dua mil laut dari Pueblo dan 17.9 mil laut dari pulau Hongdo itu, 5.9 mil di luar wilayah klaim perairan Korea Utara. Sub chaser kemudian melaporkan posisi Pueblo sebagai 18.3 mil laut dari Hongdo, 6.3 mil laut di luar perairan teritorial Korea Utara. Pueblo menyatakan dalam pesannya bahwa Sub chaser telah memberi sinyal untuk menanyakan kebangsaan Pueblo.

Pueblo memberikan jawaban atas pertanyaan dengan mengangkat bendera Amerika Serikat dan sinyal internasional untuk hidrograf. Sub chaser kemudian memberi isyarat untuk menaiki kapal tersebut atau mereka akan melepaskan tembakan dan Pueblo menjawab bahwa kapalnya berada di perairan Internasional, Sub chaser terus melingkari Pueblo. Setelah beberapa jam berikutnya Korea Utara menembaki Pueblo dengan kedua senapan dan senapan mesin yang selanjutnya dilaporkan dari Pueblo dan Korea Utara menyatakan bahwa ada empat orang yang terluka di atas kapal yang kemudian satu diantaranya meninggal. ${ }^{4}$

\section{METODE}

Paradigma yang digunakan dalam penelitian ini adalah Kontruksi (produksi dan pertukaran makna), Paradigma ini melihat komunikasi sebagai produksi dan pertukaran makna. Titik perhatian bukan bagaimana seorang mengirimkan pesan, tetapi bagamana masing-masing pihak dalam lalulintas komunikasi saling dipertukarkan dan disebarkan dan dipadukan dengan pendekatan metode Kualitatif, metode ini merupakan sebuah pendekatan untuk

\footnotetext{
4 "Youtube, dapat diakses pada alamat

https://www.youtube.com/watch?v=q9ZPCwDeSFU."
} 


\section{Dinda Rizkimawati: STUDI KOMPARASI TERHADAP.....}

mengekplorasi dan memahami makna (meaning) oleh sejumlah individu atau kelompok orang dianggap berasal dari masalah sosial dan kemanusiaan ${ }^{5}$. Dalam melakukan proses penelitian kualitatif ini peneliti mengumpulkan data dan menganalisis data secara induktif dari tema-tema khusus ketema umum.

Teknik pengumpulan data adalah suatu cara yang digunakan peneliti untuk mengumpulkan sebuah data. Data terbagi menjadi dua, yaitu data primer dan data sekunder ${ }^{6}$. Data primer adalah data yang didapatkan langsung dari sumbernya serta langsung memberikan informasi kepada peneliti terkait objek yang diteliti. Dalam penelitian ini peneliti menggunakan teknik pengumpulan data dengan dokumen ${ }^{7}$, dimana film dokumenter menjadi sumber utama serta menjadi data primer peneliti. Data sekunder adalah data yang sudah ada sebelumnya atau data yang sudah tersedia. Data sekunder tidak langsung memberikan informasi terkait objek penelitian ${ }^{8}$. Peneliti memperoleh data sekunder melalui informasi serta berita-berita yang ada di internet, seperti melalui situs. Penggunaan buku sebagai suber rujukan dan jurnal menggenai penelitian sebelunya, terkait dengan teori propaganda, konsep framing, analisa framing film sebagai media propaganda.

Teknik analisa data yang digunakan dalam penelitian ini adalah analisis framing milik Robert N. Entman yang dipadukan dengan penggunaan metode komparsi yang bertujuan untuk membandingkan isi atau pesan yang terdapat pada film dokumenter terkait insiden kapal "Pueblo" yang dilakukan Korea Utara dan Amerika Serikat. Perangkat framing yang dikembangkan oleh Robert N. Entman dapat digambarkan sebagai berikut:

${ }^{5}$ Umar Suryadi Bakry, Metode Penelitian Hubungan Internasional. (Yogyakarta: Pustaka Pelajar, 2016), h. 14.

${ }^{6}$ Sugiyono, Memahami Penelitian Kualitativ (Bandung: CV Alfabeta, 2009), h. 62.

7 Ibid, h. 62 .
${ }^{8}$ Ibid, h. 62 . 


\section{Dinda Rizkimawati: STUDI KOMPARASI TERHADAP.....}

\section{Tabel 1. Teknik Analisa Data}

\begin{tabular}{ll}
\hline $\begin{array}{l}\text { Define Problems } \\
\text { (Pendefinsian masalah) }\end{array}$ & $\begin{array}{l}\text { Bagaimana suatu peristiwa/isu } \\
\text { dilhat? Sebagai apa? Atau sebagai } \\
\text { mana apa? }\end{array}$ \\
\hline & $\begin{array}{l}\text { Peristiwa itu dilihat disebabkan } \\
\text { oleh apa? Apa yang dianggap }\end{array}$ \\
$\begin{array}{l}\text { Diagnose Causes } \\
\text { Memperkirakan masalah atau } \\
\text { sumber masalah) }\end{array}$ & $\begin{array}{l}\text { masalah? Siapa (aktor) yang } \\
\text { dianggap sebagai penyebab } \\
\text { masalah? }\end{array}$ \\
\hline \multirow{3}{*}{$\begin{array}{l}\text { Make Moral Judgement } \\
\text { (Membuat keputusan moral) }\end{array}$} & $\begin{array}{l}\text { untuk menjelaskan masalah? Nilai } \\
\text { moral apa yang dipakai untuk } \\
\text { melegitimasi suatu tindakan? }\end{array}$ \\
\hline $\begin{array}{l}\text { Treatment Recommendation } \\
\text { (Menekankan penyelesaian) }\end{array}$ & $\begin{array}{l}\text { Penyelesaian apa yang ditawarkan } \\
\text { dan harus ditempuh untuk } \\
\text { mengatasi masalah? }\end{array}$ \\
\hline
\end{tabular}

Sumber: Eriyanto, 2002. ${ }^{9}$

Pemaduan analisis Framing dengan metode komoarasi dalam penelitian ini untuk melihat perbedaan serta membandingkan isi pesan dan maksud tujuan dari dua objek penelitian yang akan diamati yaitu dua film dokumenter terkait insiden "Pueblo" yang dibuat Korea Utara dan Amerika Serikat. Perbandingan merupakan dasar prinsip ilmu penggetahuan yang dilakukan sehari-hari, menggutip pernyataan Tood Landman, membuat perbandingan merupakan aktifitas manusia yang alami, dalam betuk yang paling sederhana perbandingan dapat didefinisikan sebagai panjajaran nilai (unit variasi) atribut (properti) bersama oleh dua atau lebih benda atau kasus (unit observasi).

Metode komparasi adalah suatu metode yang digunakan untuk membandingkan data-data yang ditarik ke dalam kongklusi baru. Komparasi sendiri dari bahasa inggris, yaitu compare, yang artinya

\footnotetext{
${ }^{9}$ Eriyanto, Analisa Framing...., h. 225., t.t., h. 225.

${ }^{10}$ Suryadi Bakry, Metode Penelitian Hubungan Internasional., h. 229-230.
} 


\section{Dinda Rizkimawati: STUDI KOMPARASI TERHADAP.....}

membandingkan untuk menemukan persamaan dari kedua konsep atau lebih. Menurut Rod Hague dan Martin Harrop setidaknya terdapat empat alasan yang dianggap perlu untuk membuat perbandinggan negara dengan metode komparatif. Pertama, metode komparatif memungkinkan kontekstualisasi pengetahuan. Kedua, metode komparasi dapat mempertajam klasifikasi. Ketiga, metode komparasi memungkinkan kita untuk merancang dan menguji hipotesis.

Keempat, metode komparasi memungkinkan kita untuk membuat prediksi dengan tujuan yang dimiliki untuk membandingkan dua objek untuk melihat perbedaan yang nampak didalamnya, komparsi atau perbandingan memiliki beberapa variasi makna, seperti analisis statistik, penilaian eksperimental hingga studi sejarah. ${ }^{11}$ Metode komparasi telah lama digunakan dalam studi lintas nasional dengan pokok pembahasan perbandingan politik. ${ }^{12}$ Melvin L. Kohn dalam analisanya mengenai penelitian lintas nasional, menyebutkan empat tipe penelitian komparatif, yaitu peneltian lintas nasional (cross-national research), penelitian transnasional (transnational research), perbandinggan studi kasus (case study comparative), dan penelitian konteks budaya (cultural context research). ${ }^{13}$

\section{TINJAUAN PUSTAKA}

\section{Framing Sebagai Pendekatan Konstruktivis}

Gagasan Robert N. Entman mengenai framing memberi tekanan lebih pada teks komunikasi yang ditampilkan dan ditonjolkan/ dianggap penting oleh pembuat teks. Kata penonjolan sendiri memiliki artian pemuatan informasi lebih terlihat jelas, lebih bermakna atau lebih mudah diingat oleh khalayak. Bentuk penonjolan bisa beragam, yaitu bagaimana menempatkan suatu aspek informasi lebih menonjol dibandingkan yang lain, dengan pengulangan

\footnotetext{
${ }^{11}$ Ibid, h. 236.

12 Ibid, h. 230.

${ }^{13}$ Ibid, h. 235-236.
} 


\section{Dinda Rizkimawati: STUDI KOMPARASI TERHADAP .....}

informasi ${ }^{14}$. Dengan demikian kostruksi sosial terhadap isi dari pesan tersebut diterjemahkan dalam bentuk pengakuan (legitimasi) dan pembantahan (delegitimasi), Menggutip pernyataan Luckman (1987) dalam artikel jurnal milik Hidayat (1999) yang mengatakan bahwa konsep legitimasi dan delegitimasi dapat dipergunakan dalam mendiskusikan kajian framing media, legitimasi (legitimacy) diperoleh melalui proses legitimasi (legitimation). Hal tersebut merupakan suatu proses untuk menampilkan realitas hubungan atau atribusi kekuasaaan sebagai suatu realitas ${ }^{15}$ sedangkan Eriyanto menjelaskan dalam bukunya (2001) yang menggatakan bahwa delegitimasi berhubungan dengan seseorang atau kelompok yang dianggap tidak absah atau benar, sedangkan legitimasi berhubungan dengan sebuah pernyataan seseorang atau kelompok yang merasa absah atau benar dan memiliki dasar pembenar tertentu ketika melakukan suatu tindakan. ${ }^{16}$

Dengan kata lain, bahasa dapat digunakan sebagai alat untuk melakukan proses idefinisikan, konstruksi dan melegitimasikan suatu realitas hubungan kekuasaan. Mengutip dari artikel jurnal milik Wahyuni Choiriyati (2010) mekanisme pemanfaatannya melalui simbol atau struktur bahasa yang mampu menyajikan sebuah realitas hubungan kekuasaan tertentu sebagai suatu realitas yang alamiah, masuk akal, dan legal. Choiriyati menambahkan bahwa proses ini disertai dengan adanya reaksi untuk menolak sebuah legitimasi kekuasaan melalui delegitimasi, dapat didefinisikan proses tersebut bertujuan untuk menampilkan bentuk kekuasaan tertentu sebagai suatu

${ }^{14}$ Eriyanto, Analisa Framing (Yogyakarta: Yogyakarta: LKiS Yogyakarta, 2002), h. 186.

${ }^{15}$ Deddy N. Hidayat, "Paradigma dan Perkembangan Penelitian Komunikasi," Paradigma dan Perkembangan Penelitian Komunikasi"dalam “Jurnal Ilmu Komunikasi, Jurnal Ikatan Sarjana Komunikasi Indonesia, ” Vol. 3 (1999), 1999.

${ }^{16}$ Eriyanto, Eriyanto, Analisis Wacana: Pengantar Analisis Teks Media (Yogyakarta: LkiS, 2001) (Yogyakarta: LKIS, 2001). 


\section{Dinda Rizkimawati: STUDI KOMPARASI TERHADAP.....}

realitas yang tidak masuk akal dan tidak obyektif. ${ }^{17}$ Sehingga pengakuan yang dimiliki melalui proses legitimasi berusaha ditumbangkan dengan melakukan tindakan delegitimasi.

Legitimasi dan delegitimasi menurut Van Dijk adalah aksi sosial kompleks yang dapat dilakukan atau diperkuat dengan percakapan dan teks, dalam perlombaan ini legitimasi dan delegitimasi diimplementasikan dalam bentuk positive selfrepresentation dan negative other-representations. Mereka berlomba untuk untuk memenagkan wacana perspektif dan "klaim" kebenaran masing-masing Keduanya sama-sama bersifat diskursif dan dapat menunjukan bahwa melalui kegiatan persuasi suatu wacana dapat menghasilkan efek perubahan format prilaku dan ideologi dominan sebuah kelompok. ${ }^{18}$ Delegitimasi simbolik merujuk pada Teun A Van Dijk dalam buku Agus Sudibyo (2001) delegitimasi lazim dilakukan ketika perangkat koersif, represif dan mekanisme legal lainya dianggap tidak efektif untuk menetralisir wacana atau kekuatan musuh negara. Delegitimasi dapat dilakukan dengan beberapa cara. Pertama, memanfaatkan konteks produk, akses dan kegunaan wacana untuk menggugat legitimasi musuh negara. Kedua, legitimasi simbolik dilakukan dengan penekanan simpton-simpton negatif atau destruktif. Ketiga, delegitimasi simbolik juga dilakukan dengan memanfaatkan tokoh yang otoritatif dan legitimate untuk membuat klarifikasi, evaluasi moral dan dakwaan-dakwaan. ${ }^{19}$

Konsep mengenai framing dari Entman menggambarkan secara luas bagaimana peristiwa ditandai dan dimaknai. Terdapat empat elemen mengenai framing milik Entman yaitu, Define Problems (Pristiwa sebagai apa) merupakan elemen master framel atau bingkai paling utama. Ketika terdapat sebuah masalah, peristiwa atau isu terjadi bagaimana sebuah masalah, pristiwa atau isu tersebut

${ }^{17}$ Wahyuni Choiriyati, "Politik Identitas: Konstruksi Legitimasi Pemimpin "Ngayojokarto"” dalam "CommL ine," 2010.

${ }^{18}$ Teun Van Dijk, Ideology:A Multidisciplinary Approach. (London

(London: SAGE Publications Ltd, 1998), 1998), h. 260-262.

${ }^{19}$ Politik media dan Pertarungan Wacana. (Yogyakarta: LKIS, 2001). 


\section{Dinda Rizkimawati: STUDI KOMPARASI TERHADAP.....}

dapat dipahami secara berbeda, melalui bingkai yang berbeda ini akan menyebabkan realitas bentukan yang berbeda pula.Diagnose Causes (Siapa penyebab masalah) pada elemen kedua ini, elemen framing untuk membingkai siapa yang dianggap sebagai aktor dari suatu peristiwa. Penyebab disini memiliki artian apa (what) tetapi juga bisa berarti siapa (who), bagaimana peristiwa dipahami, tentu saja menentukan apa dan siapa yang dianggap sebagai sumber masalah. Karena itu, masalah yang pahami secara berbeda, penyebab masalah secara tidak langsug juga dipahami secara berbeda penyebab masalah secara tidak langsung akan dipami berbeda pula.

Make Moral Judgement (Penilaian atas penyebab masalah) pada bagian elemen ini bertujuan untuk membenarkan/memberi argumentasi pada pendifinsian masalah yang sudah dibuat. Ketika masalah sudah didefinisikan, penyebab masala ditemukan dan dibutuhkan arguentasi yang kuat untuk mendukung gagasan tersebut. Treatment Recommendation (Saran penanggulangan masalah) elemen ini digunakan untuk menilai apa yang dikehendaki untuk menyelesaikan masalah. Peyelesaian ini tentu saja tergantung pada bagaimana peristiwa itu dilihat dan siapa yang dipandang sebagai penyebab masalah.

Perangkat framing milik Entman memilik dua level. Pertama, konsep mental yang digunakan untuk memproses informasi dan sebagai karakteristik dari teks berita. Kedua, perangkat spesifik dari narasi berita yang dipakai untuk membangun pengertian menggenai peristiwa. Dalam buku Eriyanto, framing mempunyai implikasi penting dalam komunikasi politik, frame membatasi agar khalayak hanya memperhatikan aspek tertentu dari realitas. Seorang politisi akan menonjolkan dirinya dan menyembunyikan informasi yang merugikan untuk mendapatkan dukungan publik. ${ }^{20}$ Melalui konsep framing menurut Robert N. Entman, terdapat teknik framing yang disampaikan melalui empat elemen, yaitu:

${ }^{20}$ Eriyanto, Analisa Framing..., h. 75. 


\section{Dinda Rizkimawati: STUDI KOMPARASI TERHADAP .....}

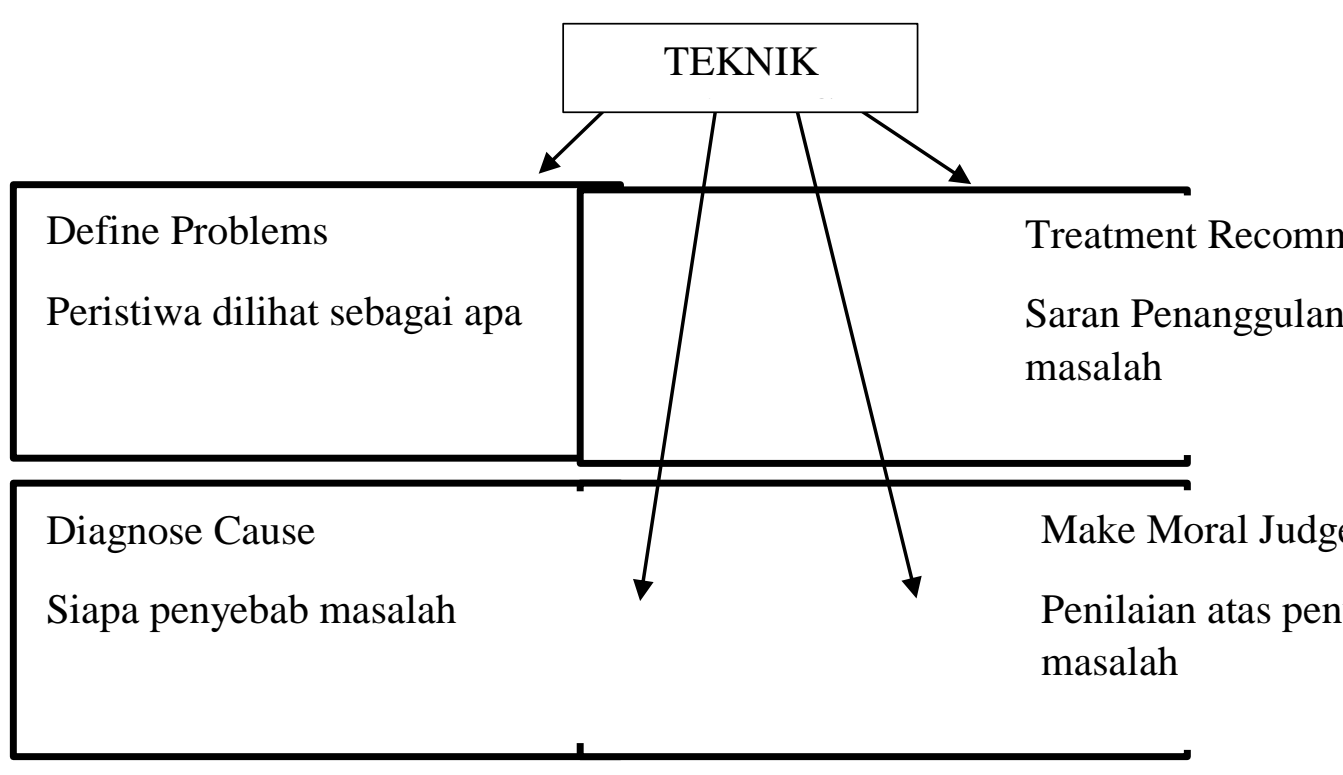

Gambar 1. Model Framing Robert N. Entman, dari Sobur, 2009. ${ }^{21}$

Teknik framing yang disampaikan oleh menurut G. Fairhurst dan R. Sarr (1996), framing memiliki beberapa teknik diantaranya (1). Metafora: Membingkai ide konseptual melalui perbandingan dengan hal lain. (2). Cerita (mitos, legenda): Membingkai topik melalui narasi dengan cara yang hidup dan mudah diingat. (3). Tradisi (ritual, upacara): adat istiadat budaya yang memberi makna penting di dunia nyata, terkait erat dengan artefak. (4). Slogan, jargon, slogan: Untuk membingkai objek dengan frasa yang mudah diingat agar lebih berkesan dan bisa berhubungan. (5). Artifak: Objek dengan nilai simbolis intrinsik - fenomena visual / budaya yang lebih memiliki makna dari pada objek itu sendiri. (6). Kontras: Untuk

${ }^{21}$ Alex Sobur, Analisis Teks Media: Suatu Pengantar untuk Analisis

Wacana, Analisis Semiotik, dan Analaisis Framing (Bandung: Pt Remaja Rosdakarya, 2009). 


\section{Dinda Rizkimawati: STUDI KOMPARASI TERHADAP.....}

menggambarkan sebuah objek. (7). Spin: untuk menyajikan sebuah konsep sedemikian rupa untuk menyampaikan penilaian nilai (positif atau negatif) yang mungkin tidak segera terlihat; untuk menciptakan bias yang melekat menurut definisi.Sehingga framing bertujuan untuk mengkonstruksi sebuah berita dan menonjolkan sebuah aspek tertentu pada sebuah peristiwa atau realitas yang dibangunoleh media. ${ }^{22}$

Hal yang menarik dari film dokumenter ini adalah ketika sebuah insiden kapal yang terjadi dibuat menggunakan dua pemaknaan yang berbeda satu sama lain. Bukan hanya itu, insiden kapal ini dibuat menjadi film dokumenter yang berisikan pesan propaganda dari Korea Utara danAmerika Serikat yang ditujukan untuk menggambarkan pesan sebenarnya dari peristiwa tersebut kepada masyarakat luas, propaganda menurut Laswell, terdapat symbol utama (master symbol atau collectictive symbol), symbol tersebut memiliki makna serta kekuatan untuk bisa menstimulasi dan mempengaruhi masa yang besar bila diaplikasikan secara luas ${ }^{23}$. Pemberian makna dengan cara yang berbeda oleh Korea Utara danAmerika Serikat dengan saling menunjukan pesan propaganda yang diproduksi melalui film dokumenter propaganda pasti termuat kepentingan didalamnya.

Pesan propaganda yang disampakan pada film dokumenter milik Korea Utara dan Amerika Serikat ini telah melalui rangkaian pembingkaian atau frame yang ditunjukan dalam adegan atau scene pada film dokumenter yang diproduksi oleh Korea Utara danAmerika Serikat, bagaimana kedua negara tersebut membingkai pesan yang ada melalui film dokumenter, film dokumenter milik Korea Utara danAmerika Serikat berusaha untuk menonjolkan pesan tertentu pada adegan yang ditampilkan melaui film dokementer tersebut. Melalui penelitian ini akan melihat bagaimana pesan propaganda yang dilakukan oleh Korea Utara danAmerika Serikatdidalamfilm

22 "https://masscommtheory.com/theory-overviews/framing-theory/.,"
${ }^{23}$ Baran Davis, D. K S. J, Mass Communication Theory: Foundations, Ferment, and Future (Boston: Wadsworth, 20011), h. 84. 


\section{Dinda Rizkimawati: STUDI KOMPARASI TERHADAP .....}

dokumenter yang diproduksi menggunakan fakta, kebenaran, dan sumber lainya yang mendukung kegiatan propaganda mereka. Pembingkaian cerita yang disampaikan melalui film dokumenter kedua negara berusaha untuk memperlihatkan kekuatan dan kelemahan lawannya, setiap adegan yang ditampilkan berusaha untuk membenjtuk persepsi publik yang melihat film dokumenter tersebut.

Selain membentuk fakta dan hanya memilih mana saja fakta yang akan disajikan untuk khalayak luas, diperlukanya kegiatan untuk menambah keyakinan khlayak agar memiliki pirian atau jalan fikir yang sama dengan pembuat pesan. Susupan materi propaganda akhirnya menjadi salah satu peran penting dalam penyajiannya, Propaganda memiliki arti suatu tindakan untuk menyebarluasakan ideide tertentu kepada masyarakat, baik secara langsung atau melalui media. ${ }^{24}$ Propaganda juga diartikan sebagai usaha dengan sengaja dan sistematis, untuk membentuk persepsi, memanipulasi pikiran, dan mengarahkan ketakutan untuk mendapatkan reaksi yang dinginkan (Garth \& O'Donnell, 2012, pp. 2-4). Sehingga propaganda dapat dijadikan sebagai sebuah tools untuk mempengaruhi persepsi dan kognisi seseorang agar mempunyai pemikiran yang sama dengan pelaku propagandis.

Berdasarkan sumber dan keakurasian informasi, Jowett danO'Donnell (2012) mengklasifikasikan propaganda kedalam tiga bentuk, yaitu white, grey, dan black propaganda. ${ }^{25}$ White propaganda adalah propaganda yang berasal dari sumber yang benar dan informasi dalam pesan cenderung akurat. Tujuan dari White proganda untuk membangun kredibilitaspelaku propaganda yang nantinya dapat digunakan untuk kepentingan tertentu. Black propaganda terjadi ketika sumber informasinya berasal dari pihak yang salah dan menyebarkan kebohongan, rekayasa, dan penipuan. Keberhasilan atau kegagalan

${ }^{24}$ Munthe M. G, "Propaganda dan Ilmu Komunikasi," Propaganda dan Ilmu Komunikasi, (Universitas Multimedia Nusantara, 2012), t.t., h. 45.

${ }^{25}$ Garth S, J., \& O'Donnell, V, Propaganda \& Persuasion (5th ed.). Thousand Oaks, California, (United State of America: SAGE Publications, Inc, 2012), (America: SAGE Publications Ltd, 1998), 2012), h. 17-24. 


\section{Dinda Rizkimawati: STUDI KOMPARASI TERHADAP.....}

dari sebuah Black propaganda bergantung pada keinginan penerima pesan dalam menerima kredibilitasdari sumber dan konten pesannya.Grey Propaganda berada diantara White dan Black propaganda. Sumbernya bisa saja diidentifikasi benaran atau tidak dan keakurasian dariinformasinya tidak pasti. Grey propaganda biasanya juga digunakan untuk mempermalukan musuh atau kompetitornya.

Menurut Institute of Propaganda Analysis, terdapat tujuh teknik propaganda, yaitu ${ }^{26}$ (1). Name Calling, (2). Glittering Generalities, (3). Transfer, (4). Testimonial, (5). Plain folks, (6). Card stacking, dan (7). Bandwagon. Name Calling adalah teknik propaganda menggunakan kata-kata yang memiliki konotasi atau pengertian negative sehingga dapat merusak nama baik orang lain atau grup. Glittering Generalities merupakan suatu upaya untuk menggugah emosi orang lain dengan menggunakan kata-kata yang dapat memberikan harapan dan mengandung kebajikan seperti "keadilan", "kebebasan", "kebenaran", "kesetaraan", "kehormatan", "ketulusan", "pahlawan", dan "kebijaksanaan". Kata-kata tersebut sebenarnya adalah kata yang abstrak dan tidak spesifik, tetapi dapat memberikan makna yang mendalam dan nilai budaya. Sehingga sering digunakan oleh pelaku propaganda (propagandist), karena power yang dimiliki kata-kata tersebut dapat mengubah persepsi target propaganda. Transfer merupakan teknik Propoganda yang dilakukan dengan memanfaatkan figure atau tokoh tertentu yang langsung tampil dan membawakan gagasan dari pihak propaganda.Testimonial adalah teknik Propoganda yang dilakukan dengan memanfaatkan figure atau tokoh tertentu yang langsung tampil dan membawakan gagasan dari pihak propaganda. Plain folks adalah sebuah alat yang digunakan oleh politikus, pemimpin buruh, pengusaha, dan bahkan menteri dan pengajar untuk mendapatkan kepercayaan dengan muncul sebagai "orang biasa". Contohnya, dalam masa pemilihan umum, para

26،"http://bassettchs.weebly.com/uploads/1/3/3/8/13382285/how_to_detect_ propaganda.pdf, h. 1-4,”. 


\section{Dinda Rizkimawati: STUDI KOMPARASI TERHADAP.....}

kandidat akan menunjukan kepada khalayak umum bahwa dirinya adalah masyarakat umum dan biasa, serta sama dengan yang lainnya.

Card stacking adalah sebuah alat dimana propagandis menggunakan semua seni penipuan untuk memenangkan dukungan untuk dirinya sendiri, kelompoknya, bangsa, ras, kebijakan, praktik, keyakinan, atau cita-cita. Card Stacking menggunakan tipuan, kemunafikan, dan kelancangan. Para pelaku propaganda menyusun kartu melawan kebenaran, menggunakan under-emphasis dan overemphasis untuk menghindari masalah dan menyeberang fakta, melakukan kebohongan, sensor dan distorsi, menghilangkan fakta, menawarkan kesaksian palsu, menciptakan tabir asap keributan dengan mengangkat isu-isu baru ketika ia ingin suatu hal yang memalukan agar dilupakan, mengalihkan perhatian untuk mengacaukan dan mengalihkan merek adalam pencarian fakta yang tidak ingin diungkapkan, membuat yang tidak nyata tampak nyata, serta membiarkan setengah-kebenaran menyamar sebagai kebenaran.

Bandwagon adalah kondisi dimana propagandis menyewaruang, stasiun radio, mengisi stadion besar, parade yang diikuti satu juta atau setidaknya banyak orang yang mengikuti parade. Pelaku propaganda menggunakan simbol, warna, musik, gerakan, dan semua seni drama. Pelaku tersebut membuat kita menulis surat, mengirim telegram, dan berkontribusi karena suatu alasan. Propagandis menarik sebagian besar dari kita, untuk mengikuti sekelompok orang banyak. Karena pelaku propaganda ingin agar masyarakat mengikuti suatu kelompok yang terdiri dari banyak orang, Pelaku propaganda menunjukan keinginannya. Kelompok-kelompok yang sudah terikat oleh ikatan umum, ikatan kebangsaaan, agama, ras, jenis kelamin, keahlian.

HASIL DAN PEMBAHASAN

Tabel 2. Unit Analisis Film Dokumenter Korea Utara

\begin{tabular}{lll}
\hline Frame & Konten & Interpretasi \\
\hline
\end{tabular}




\section{Dinda Rizkimawati: STUDI KOMPARASI TERHADAP.....}

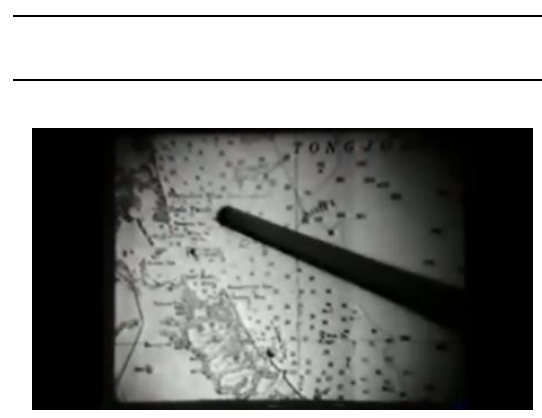

$04: 42$

\section{Pemberitaan}

Define
Problems
Film dokumenter
milik Korea
Utara dengan
judul Pueblo:

Armed Spy Ship of the US

Imperialist

dengan sudut visualisasi yang menampilkan salah satu kru kapal Letnan Edward R Murphy sebagai petugas administrasi yang menjelaskan posisi kapal Pueblo saat itu berada pada jarak 7.6 mil laut dari pulau Ryo dilaut Wonsan
Dalamfilm

dokumenter milik

Korea Utara dengan judul Pueblo: Armed Spy Shp of the US Imperialist, Korea Utara membingkai pesan bahwa bukti perjalanan kapal melalui peta tersebut yang ditujukan oleh petugas kapal, menunjukan keberadaan kapal Pueblo berada pada posisi 7,6 mil laut dari pulau Ryo dilaut Wonsan. Korea Utara ingin menggambarkan pada publik bahwa kapal Pueblo telah melakukan pelanggaran terotorial dengan pembuktian melalui peta serta 
Dinda Rizkimawati: STUDI KOMPARASI TERHADAP .....

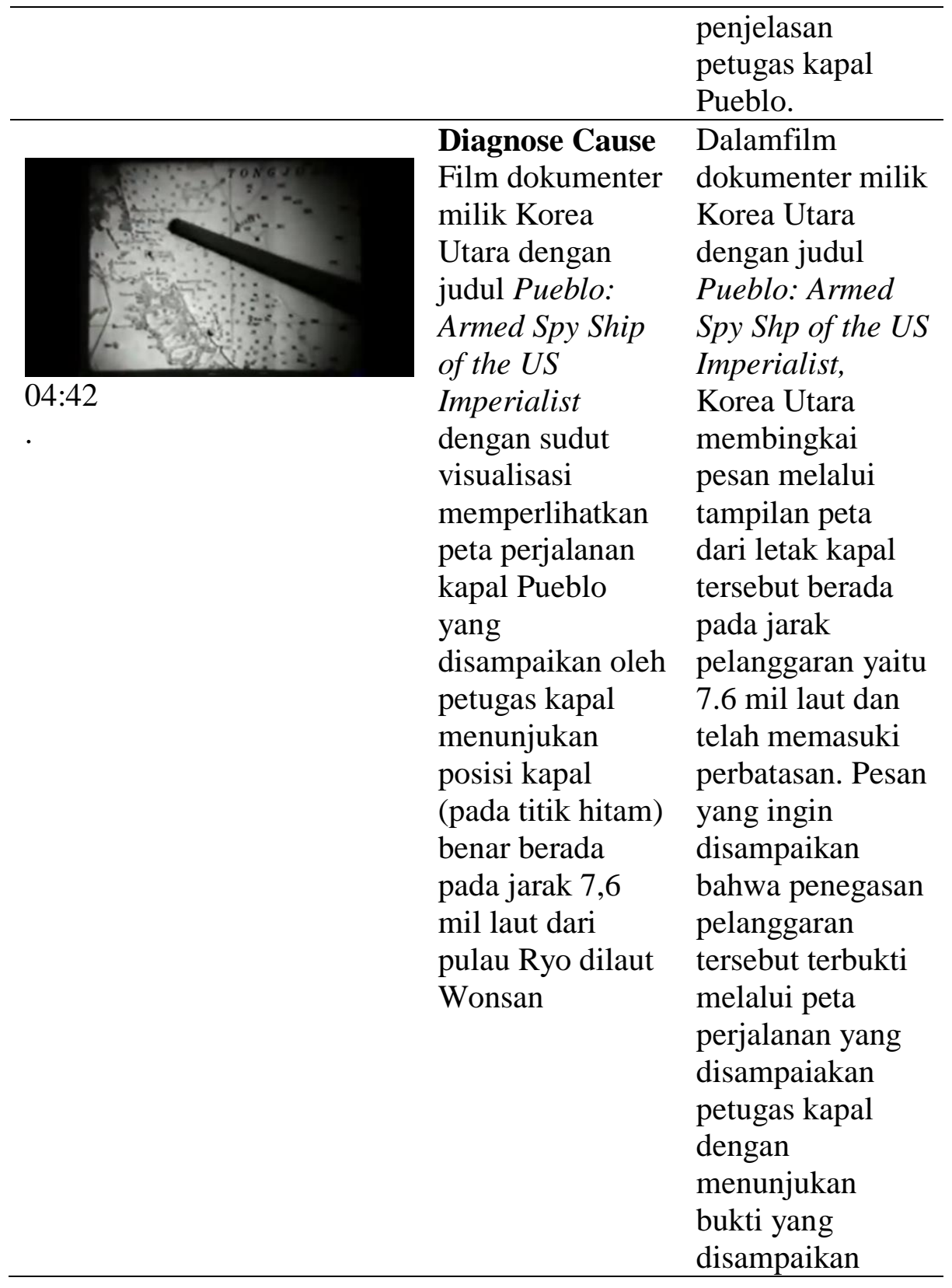




\section{Dinda Rizkimawati: STUDI KOMPARASI TERHADAP .....}

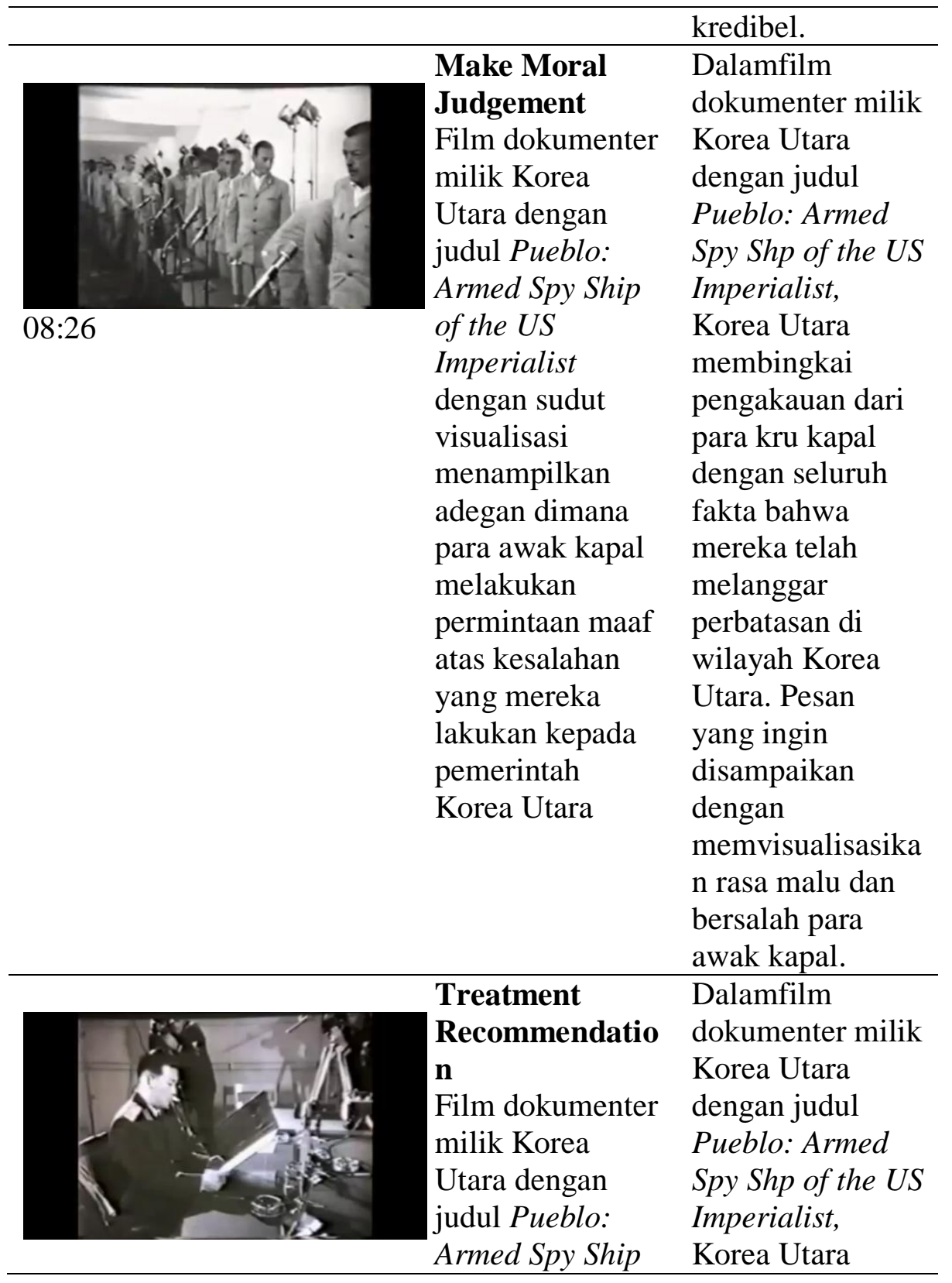




\section{Dinda Rizkimawati: STUDI KOMPARASI TERHADAP.....}

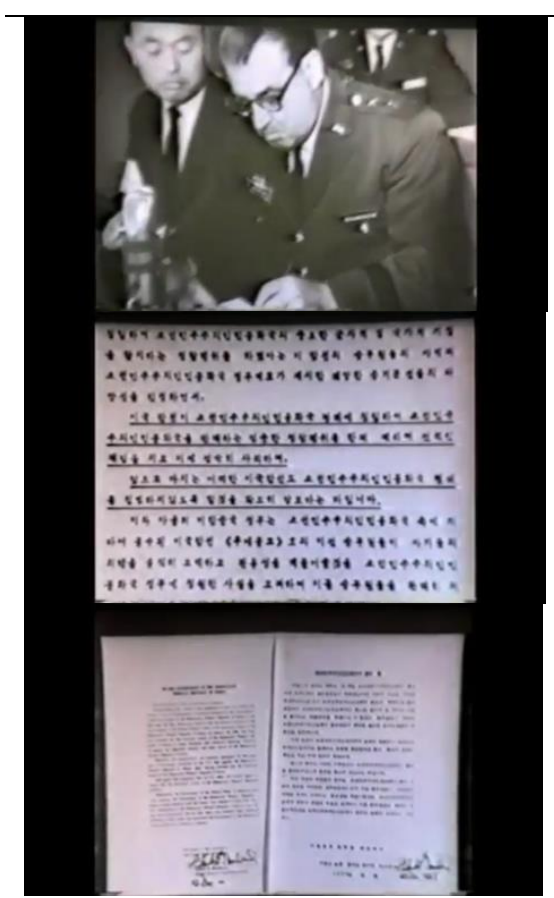

$10: 31-11: 46$

of the US
Imperialist
dengan sudut
visualisasi
menampilkan
beberapa adegan
yang
menunjukan
adegan
penandatanganan
kesepakatan
yang diminta
oleh Korea Utara

Imperialist dengan sudut visualisasi menampilkan yang menunjukan adegan penandatanganan kesepakatan yang diminta oleh Korea Utara membingkai pesan bahwa Amerika Serikat mengakui kesalahan yang mereka perbuat dengan bukti penandatanagana n permintaan maaf resmi dari pemerintah Amerika Serikat kepada pemerintah Korea Utara dan berjanji tidak akan terjadinya hal tersebut dikemudian hari. Pesan yang ingin disampaikan adalah kemenangan mutlak Korea Utara atas insiden Pueblo yang dengan perjanjian yang telah disepakati.

Sumber: Data olahan peneliti, 2017.

Pendekatan framing milk Robert N. Entman mengenai film dokumenter milik Korea Utara dengan judul Pueblo: Armed Spy Ship of the US Imperialist menunjukan bahwa arah penceritaan yang 


\section{Dinda Rizkimawati: STUDI KOMPARASI TERHADAP.....}

dilakukan Korea Utara melalui film dokumenter ini memiliki tujuan untuk mempengaruhi persepsi publik bahwa Korea Utara merupakan negara yang lebih kuat atas Amerika Serikat dengan bukti kemenangan disertai dengan permintaan maaf resmi pemerintah Amerika Serikat kepada pemerintah Korea Utara. Hal ini ditunjukan melalui pembingkaian yang dilakukan pada film dokumenter dengan dominasi kekuatan dan keberhasilah Korea Utara dalam adegan yang ditampilkan.

Define Problems dalam bingkai film dokumenter milik Korea Utara dengan judul Pueblo: Armed Spy Ship of the US Imperialist adalah pengakauan dari petugas kapal yang menerangkan jarak kapal yang berada pada jarak 7.6 mil laut hal ini membuktikan bahwa tuduhan yang disampaikan benar. Diagnose Cause bingkai film dokumenter tersebut diisi dengan menampilkan peta perjalan kapal yang menunjukan letak kapal yang berada pada posisi pelanggaran dengan jarak 7.6 mil laut, dengan penggunan peta perjalanan yang diklaim milik Amerika Serikat ini menunjukan tuduhan tersebut bukan kesalahan.

Make Moral Judgement dalam bingka tersebut menampilkan rasa malu dan bersalah para awak kapal dengan meminta maaf kepada pemerintah Korea Utara pada acara 20 tahun perayaan yayasan Democratic People's Republic of Korea. Pesan yang ingin disampaikan bahwa pengakuan yang dilakaukan oleh kru kapal didepan wartawan dari berbagai negara menunjukan kesalahan Amerika Serikat pada dunia. Treatment Recommendation menampilkan pertemuan antara pemimpin dua negara tersebut yaitu Kim Jong Il dan Presiden Johnson yang melakukan perjanjian, menampilkan pesan bahwa Amerika Serikat mengakui kesalahanya yang sengaja melanggar perbatasan.I

Uraian di atas menyimpulkan bahawa nilai kebenaran atas penyampaian fakta dalam film dokumenter ini telah telah memfokuskan, melebihkan serta mengurangi beberapa fakta yang menyampaiakan kronologi dari insiden kapal Pubelo yang tertangkap pada tanggal 23 Januari 1968. 


\section{Dinda Rizkimawati: STUDI KOMPARASI TERHADAP .....}

\section{Tabel 3. Unit Analisis Film Dokumenter Amerika Serikat}

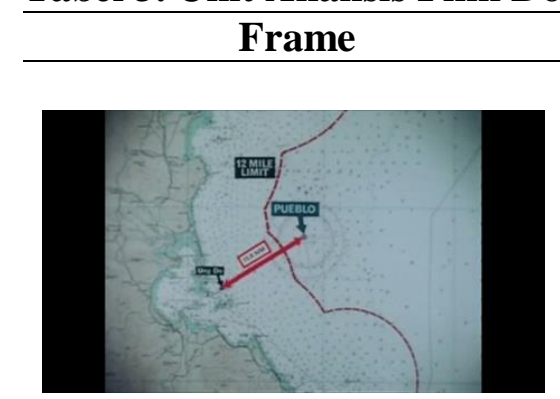

$02: 28$
Konten Pemberitaan

Define Problems

Film dokumenter milik

Amerika Serikat dengan judul The Pueblo Incident Analysis of the North Korea Evidance dengan sudut visualisasi yang menjelaskan posisi kapal Pueblo oleh Letnan Douglas M Hackett seorang Officer of Naval Intelligence saat itu berada pada jarak 15.8 mil laut dari daratan terdekat Hong Do.

Interp Dalamfilm dok milik Amerika dengan judul $T$ Incident Analy North Korea E Amerika Serik membingkai $\mathrm{p}$ kapal melalui 1 perjalanan yan oleh seorang $O$ Naval Intellige menunjukan $\mathrm{ke}$ kapal Pueblo b posisi $15.8 \mathrm{mil}$ daratan terdek: Amerika Serik memberikan ga publik bahwa 1 tidak berada pe yang melangga dan tidak berac penangkapan $\mathrm{s}$ dituduhkan ole Utara.

Diagnose Cause

Film dokumenter milik Amerika Serikat dengan judul The Pueblo Incident Analysis of the North Korea Evidance dengan sudut
Dalamfilm dok milik Amerika dengan judul $T$ Incident Analy North Korea E Amerika Serik 


\section{Dinda Rizkimawati: STUDI KOMPARASI TERHADAP.....}

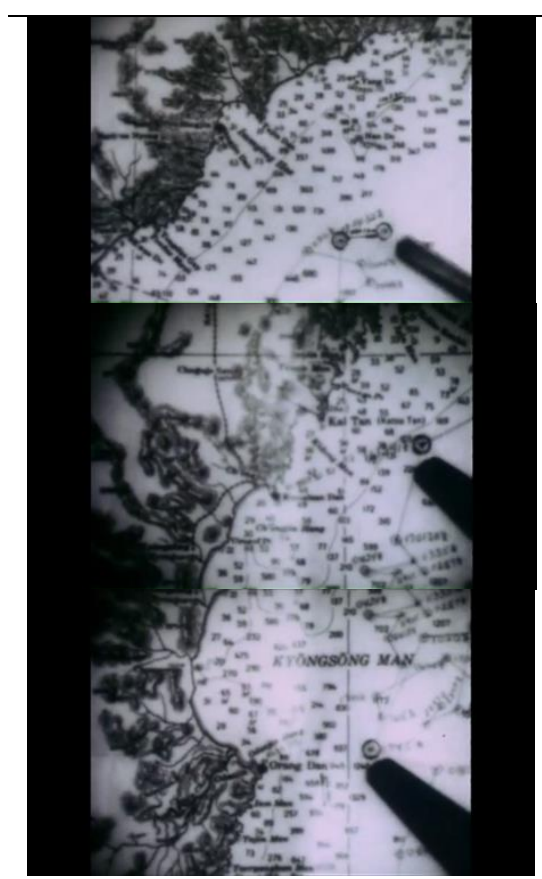

26:03-26:26

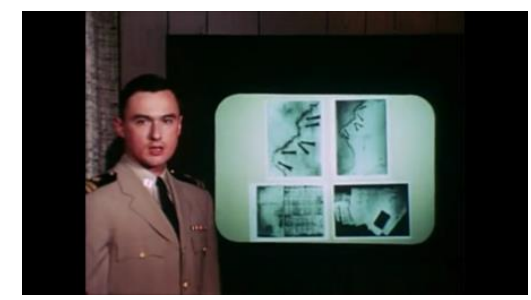

11:08 visualisasi memperlihatkan penjelasan dari kutipan film dokumenter Korea Utara yang menampilkan peta perjalanan kapal Pueblo yang disampaikan oleh petugas kapal menunjukan posisi kapal pada peta tersebut berubah-ubah dah jarak terdekat kapal Pueblo pun berubah dari letak yang disampaikan sebelumnya. membingkai $\mathrm{pe}$ tampilan peta $\mathrm{u}$ posisi kapal ya ubah, dari kuti] dokumenter mi Utara bahwa $\mathrm{p}$ perjalanan yan: tidak sesuai de pertaman. Pesa disampaikan $b$ Utara berada $p$ inkonsistensi $\mathrm{p}$ yang mereka s kepada dunia, menegaskan bc informasi yang sampaikan atal tidaklah kredib

\section{Make Moral Judgement}

Film dokumenter milik Amerika Serikat dengan judul The Pueblo Incident Analysis of the North Korea Evidance dengan sudut visualisasiyang menggambarkan sorang pemandu dalam film dokumenter ini menunjukan beberapa bukti yang dipalsukan oleh Korea Utara mulai dari dua peta posisi penengkpan, log, dan beberapa dokumen yang
Dalamfilm dok milik Amerika dengan judul $T$ Incident Analy North Korea E Amerika Serik: membingkai p semua bukti ya disampaika ata ditampilkan ol Utara adalah d palsu dan kobo untuk memper Amerika Serik melanggar pert 


\section{Dinda Rizkimawati: STUDI KOMPARASI TERHADAP.....}

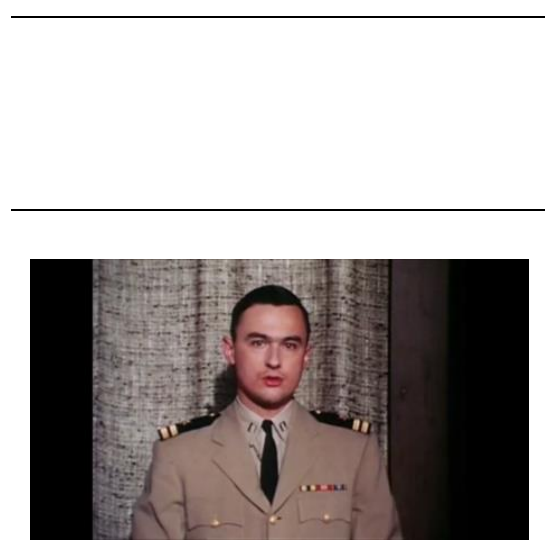

27:31 berasal dari Pueblo

Treatment

Recommendation

Film dokumenter milik

Amerika Serikat dengan

judul The Pueblo Incident

Analysis of the North Korea

Evidance dengan sudut

visualisasimenampilkan

adegan kesimpulan dari film

dokumenter ini bahwa bukti

ganguan yang disampaikan

adalah rekayasa dan tidak

konsisten.
Pesan yang ing

disampaikan as

benaran atas se

dan pembohon

Dalamfilm

milik Amer

dengan judul

Incident Ana

North Korec

Amerika

membingkai

ketidak

perbedaan sert yang membuk mereka. Pesar disampaikan rekayasa yang seluruhnya sal sampai akhir.

Sumber: Data olahan peneliti, 2017.

Pendekatan framing milk Robert M. Entman mengenai film dokumenter milik Amerika Serikat dengan judul The Pueblo Incident Analysis of the North Korea Evidance menunjukan bahwa arah cerita yang dilakukan Amerika Serikat melalui film dokumenter ini memiliki tujuan untuk menyampaiakan pesan mempengaruhi persepsi publik. Persepsi adalah gambaran yang diterima rangsangan melalui pancaindera dengan sebuah kesadaraan yang didahului setelah terjadi proses pengamatan terhadap sesuatu Bahwa Korea Utara telah melakukan kesalahan dengan menagkap kapal yang berada pada zona perairan internsional, Amerika Serikat memberikan bukti perjalan yang sebernya melalui film dokementer ini. Hal ini ditunjukan melaui pembingkaan yang dilakukan pada film dokumenter dengan dominasi pembuktian yang dijabarkan pihak Amerika Serikat. 


\section{Dinda Rizkimawati: STUDI KOMPARASI TERHADAP.....}

Define Problems dalam bingkai film dokumenter milik Amerika Serikat dengan judul The Pueblo Incident Analysis of the North Korea Evidance adalah menunjukan letak posisi kapal yang berbeda dengan klim Korea Utara, peta tersebut menunjukan jarak kapal berada pada 15.8 mil laut. Dengan demikian apa yang diakui oleh Korea Utara tidaklah benar, Diagnose Cause bingkai film dokumenter tersebut diisi dengan tindakan inkonsistensi yang dilakukan Korea Utara. Penampilan peta kapal dengan jarak penagkapan yang berbeda-benda Amerika Serika ingin menunjukan apakah bukti yang diklaim oleh Korea Utara dapat dipercayai atau bukti yang kredibel.

Make Moral Judgement dalam bingka tersebut menunjukan kebohongan yang dilakukan Korea Utara dengan memberikan bukti palsu. Pelampiran dokumen yang dijadikan klaim oleh Korea Utara tidaklah benar karena menunjukan banyaknya perbedaan dan inkonsistensi data. Treatmen Recommendation yang ditampilkan oleh Amerika Serikat menampilkan pembahasan yang menerangkan jika pembahasan yang disampaikan Korea Utara tidak memiliki kebenaran dan inkonsistenasi dalam memaparkan bukti. Uraian narasi diakhir tayangan ingin menyampaikan pesan bahwa apa yang disampaikan Korea Utara patut dipertanyakan kebenaranya dan membuka kembali perdebatan tentang insiden penangkapan kapal Pueblo.Uraian di atas menyimpulkan bahawa nilai kebenaran atas penyampaian fakta dalam film dokumenter ini telah telah memfokuskan, melebihkan serta mengurangi beberapa fakta yang menyampaikan kronologi dari insiden kapal Pubelo yang tertangkap pada tanggal 23 Januari 1968.

\section{KESIMPULAN}

Dapat disimpulkan bahwa film dokumenter milik Korea Utara (Pueblo: Armed Spy Ship of the US Imperialist) dan Amerika Serikat (The Pueblo Incident Analysis of the North Korea Evidance) yang menceritakan insiden penangkapan kapal Pueblo yang terjadi pada tanggal 23 Januari 1968, menunjukan perbedaan bentuk melalui tayangan yang ditampilkan Korea Utara (Pueblo: Armed Spy Ship of 


\section{Dinda Rizkimawati: STUDI KOMPARASI TERHADAP.....}

the US Imperialist) dan Amerika Serikat (The Pueblo Incident Analysis of the North Korea Evidance). Melalui film dokumenter ini memperlihatkan bukti yang berbeda dan bertolak belakang. Penulis melihat pesan yang ingin disampaikan Korea Utara melalui film dokumenter Pueblo: Armed Spy Ship of the US Imperialist dalam konteks ini Korea Utara berusaha menunjukan pada pihak luar dengan mendelegtimasi keberadaan Amerika Serikat dalam konteks sistem internasional dan hubungan internasional, sedangkan kedalam Korea Utara berusaha melegitimasi bahwa pemerintahan Korea Utara kuat dihadapan negara besar sekalipun.

Apa yang ditampilakan Amerika Serikat melalui film dokumenter The Pueblo Incident Analysis of the North Korea Evidancemenunjukan kepada pihak luar dengan bentuk mendelegitimasi setiap bukti yang disampaikan oleh Korea Utara dengan menunjukan inkonsistensi lawan melalui bukti yang berubahubah, sedangkan kedalam, Amerika Serikat berusaha melegitimasi kebenaran yang ada melalui bukti yang dimilki dan menjelaskan bukti yang disampaikan Korea Utara salah. Dengan demikian ketidak konsistenan, perbedaan dan kontradiksi, menggenai bukti tuduhan yang dimiliki Korea Utara merupakan rekayasa yang lengkap dan seluruhnya salah dari awal sampai akhir.

Oleh karena itu, di akhir penelitian ini, penulis menyimpulkan bahwa di setiap media masa yang memuat makna dan pesan-pesan terdapat perbedaan framing dan bias kepentiangan, sedangkan topik yang diangkat pada penelitian ini tidak terlepas dari koridor upaya propaganda yang dilakukan kedua negara dengan menampilkan fenomena historis yang menampilkan kepentingan. Oleh sebab itu, dapat dimaklumi terdapat perbedaan framing diantara kedua film dokumenter terkait insiden kapal Pueblo. 


\section{Dinda Rizkimawati: STUDI KOMPARASI TERHADAP .....}

\section{DAFTAR PUSTAKA}

Bakry, U. S, Metode Penelitian Hubungan Internasional, Yogyakarta, Pustaka Pelajar, 2016.

Baran, S. J., \& Davis, D. K, Mass Communication Theory: Foundations, Ferment, and Future. Boston, Wadsworth, 2011.

Choiriyati, W, Politik Identitas: Konstruksi Legitimasi Pemimpin "Ngayojokarto", CommLine, Jurnal Ilmu Komunikasi, 1(2). 2010.

Dijk, T. V, Ideology: A Multidisciplinary Approach, London, SAGE Publications Ltd, 1998.

Eriyanto, Analisa Framing. Yogyakarta, DI Yogyakarta, LKiS Yogyakarta, 2002.

Eriyanto, Analisis Wacana: Pengantar Analisis Teks Media. Yogyakarta, LkiS, 2001. Diperoleh dari https://books.google.co.id/books?id=cpDAPMAmimcC\&pg=P A118\&lpg=PA118\&dq=wacana+legitimasi + dan + delegitimasi \&source=bl\&ots=CdrnrF3oXm\&sig=159RpXPSycuZzLPvh_ Fwe9s94uI\&hl=id\&sa=X\&ved=0ahUKEwighpfn9HaAhXLPo8KHRZTAaMQ6AEISzAG\#v=onepage \&q=waca na\%20legitimasi\%20dan\%20delegitimasi\&f=false

Garth S, J., \& O'Donnell, V, Propaganda \& Persuasion (5th ed.). Thousand Oaks, California, United State of America, SAGE Publications, Inc, 2012.

Gunnar. (n.d.). How to Detect Propaganda. Diperoleh dari Institute of Propaganda Analysis: 


\section{Dinda Rizkimawati: STUDI KOMPARASI TERHADAP.....}

http://bassettchs.weebly.com/uploads/1/3/3/8/13382285/how_t o_detect_propaganda.pdf

Hadjimatheou, C. (23 Januari 2012,). Sailor recalls 1968 North Korean capture of USS Pueblo. Diperoleh dari BBC: http://www.bbc.com/news/world-asia-16650683

Hidayat, D. N, Paradigma dan Perkembangan Penelitian Komunikasi. Jurnal Ilmu Komunikasi, Jurnal Ikatan Sarjana Komunikasi Indonesia, 1999.

Koryo Media. (2016, September 14). DPRK History: US Armed Spy Ship Pueblo. North Korea [File Video]. Diperoleh dari https://www.youtube.com/watch?v=lmAhuIGbdBs

Mass Communication Theory. (n.d.). Diperoleh dari Framing Theory: https://masscommtheory.com/theory-overviews/framingtheory/

Munthe, M. G, E-journal: Propaganda dan Ilmu Komunikasi, 2012. Diperoleh dari Universitas Multimedia Nusantara: http://library.umn.ac.id/jurnal/public/uploads/papers/pdf/bafb5 035c726c8b31fe8931ef50db1cd.pdf

Santosa, T. (19 April 2014). Film Insiden Pueblo 1968. Diperoleh dari Kantor Berita Politik RMOL.CO: http://www.rmol.co/read/2014/04/19/151865/770/FilmInsiden-Pueblo-1968-

Sobur, A, Analisis Teks Media: Suatu Pengantar untuk Analisis Wacana, Analisis Semiotik, dan Analaisis Framing. Bandung, Pt Remaja Rosdakarya, 2009.

Sudibyo, A., Politik media dan Pertarungan Wacana. Yogyakarta:LkiS, 2001.

Sugiyono, Memahami Penelitian Kualitativ. Bandung, CV Alfabeta, 2009.

North Korea to put US spy ship captured in 1968 on display The Guardian. (25 Juli 2013). Diperoleh dari: https://www.theguardian.com/world/2013/jul/25/north-koreaus-spy-ship-museum 


\section{Dinda Rizkimawati: STUDI KOMPARASI TERHADAP.....}

US National Archives. (2010, Desember 22). The Pueblo Incident: Analysis of the North Korean Evidence. [File Video]. Diperoleh dari https://www.youtube.com/watch?v=q9ZPCwDeSFU 